J. Clin. Chem. Clin. Biochem.

Vol. 26, 1988 , pp. $531-540$

(C) 1988 Walter de Gruyter \& Co.

Berlin · New York

\title{
Performance of a Three-Part Dif Impedance Cytometer (Sysmex E-4000) in Comparison with a Cytochemical Cytometer (Technicon H 6000) $)^{1}$ )
}

\author{
By E.H.J. Smeets and J.W.J. van Wersch \\ Hematological Laboratory, De Wever Hospital, Heerlen, Netherlands
}

(Received November 11, 1987/April 28, 1988)

Summary: Particle-size analysis of leukocytes with cytometers based on the impedance method makes it possible to distinguish three types of white cells in blood (small cells, medium-sized cells and large cells). In order to test the ability of such a three-part dif cytometer to screen for abnormal cells of the leukocyte series, we assayed the differentiation of white cells in 786 blood samples with the Sysmex E-4000 and compared the results with those of the Technicon $\mathrm{H6000}$, a cytochemical cytometer. The small cell and large cell fractions of the Sysmex E-4000 correlated very well with the percentages of lymphocytes and neutrophils measured with the Technicon instrument and showed good sensitivity and specificity in discriminating samples with normal and abnormal results. The percentage of the medium-sized cells correlated significantly with the contents of eosinophilic, monocytic and basophilic cells as assayed with the Technicon H6000; but for a satisfactory determination of each of these cell lines (sensitivity of more than $90 \%$ and ca. $70 \%$ specificity) it was necessary for them to represent more than $10 \%$ of the medium-sized cell population.

The red cell parameters of both cytometers were compared in 695 samples. All parameters, which were not based on measurement of the red cell volume, exhibited an excellent agreement for both instruments. The mean haematocrit and the average mean corpuscular volume (MCV) were significantly higher and the average mean corpuscular haemoglobin concentration (MCHC) and absolute distribution width (ADW) were significantly lower in the Sysmex E-4000. The mean difference of MCV between both cytometers increased for microcytic and macrocytic cells. There was a great interindividual variation of $\triangle \mathrm{MCV}$. No relation between MCHC and mean corpuscular haemoglobin (MCH) was found with the Sysmex E-4000 for normocytic and macrocytic cells, although a significant relation existed for small red cells as a result of overestimation of the $\mathrm{MCV}$ in cells with low $\mathrm{MCH}$. In the Technicon $\mathrm{H} 6000$ the $\mathrm{MCHC}$ correlated significantly with the $\mathrm{MCH}$ in normocytic and macrocytic cells, due to underestimation of MCV in these cells. With the Sysmex E-4000 a greater interindividual variation of $\mathrm{MCV}$, and of $\mathrm{MCHC}$ in relation to $\mathrm{MCH}$ was measured than with the Technicon H6000. Possible explanations of these findings are discussed.

\footnotetext{
') Abbreviations used:

SCR. small cell ratio

LCR large cell ratio

MCR middle cell ratio

MCV mean corpuscular volume = haematocrit/erythrocyte count

$\mathrm{MCH}$ mean corpuscular haemoglobin = $\mathrm{Hb}$ concentration/erythrocyte count

$\mathrm{MCHC}$ mean corpuscular haemoglobin content $=\mathrm{Hb}$ concentration/haematocrit

ADW absolute distribution width of the red blood cell volume histogram

RDW relative distribution width of the red blood cell volume histogram

LUC large unstained cell in Technicon H6000

$r \quad$ Pearson correlation coefficient
}

\begin{abstract}
Introduction
The advent of flow cytometry has brought many benefits to haemocytometry, e.g. enhanced precision, faster analysis rate and advanced automation of the workload. However, the accuracy of the results still gives cause for concern, depending on the physical principle of cell counting and sizing, the diluent and reagents used and the technical details of the numerous cytometers, which have been developed for the performance of multiparameter haematological determinations. For a recent review see 1.c. (1).
\end{abstract}


Improved discrimination in the analysis of the particle size of leukocytes in so-called three-part dif cytometers enables us now to discern three populations of white blood cells from the volume histogram of the leukocyte series in blood (2). In the Sysmex E-4000 cytometer these populations are characterized as follows:

1. small cells representing lymphocytes, of which the result is reported as the small cell ratio (SCR);

2. large cells representing mainly neutrophilic granulocytes, reported as the large cell ratio (LCR); and 3. medium-sized cells representing a mixed population of monocytes, eosinophilic and basophilic granulocytes, reported as the middle cell ratio (MCR).

In order to test the capabilities and the limitations of this so-called three-part dif, a comparison with manual microscopic examination of a great number of cells $(>1000)$ would be preferable. However, performance of a statistically desirable number of such differentiations is extremely time consuming, while the routinely used standard 100-cell differentiation is fraught with poor precision $(3-5)$ and low sensitivity $(6-8)$, when used as a screening test. Therefore we compared the results of the Sysmex E- 4000 with those of the Technicon H6000, a cytochemical flow haemocytometer, which has shown good precision and close agreement with the results of manual differentiations in this and other laboratories $(9-11)$.

In the Sysmex E-4000 red blood cells are counted and their cell volume is assessed by measuring the change of impedance, when the particles pass through a sensing aperture in a hydrodynamically focussed sheathed sample stream. In the Technicon H6000 cytometer cells are also counted in a hydrodynamically focussed sheathed sample stream, but sizing of the red blood cells is based on measurement of light scattering by the particles. Moreover the red cells are isovolumetric sphered in order to eliminate variations in signal size dependent on variations in shape and orientation of the biconcave erythrocytes $(12,13)$. The second aim of this study was therefore to compare the red blood cell results of both cytometers and to investigate how the different methods for measurement of cell volume influence the results of the mean corpuscular volume (MCV) and the mean corpuscular haemoglobin concentration (MCHC) in red blood cells of several sizes.

\section{Materials and Methods}

\section{Materials}

We included blood samples of 695 patients (42\% inpatients and $58 \%$ outpatients) in the study without selection. In this collection relative few samples with more than slightly increased pcrcentages of lymphocytes, eosinophils or monocytes were present. To evaluate the analytical performance of the middle cell ratio MCR and small cell ratio SCR we therefore included further samples, exhibiting elevated levels of lymphocytes, eosinophils or monocytes.

Venous blood $(5 \mathrm{ml})$ was collected in vials containing $7.5 \mathrm{mg}$ EDTA-K $\mathrm{K}_{2}$ (Monoject, Sherwood). Samples were kept for 30 min to 4 hours at room temperature before they were run both on the Technicon H6000 cytometer (Technicon Instruments Corp., Tarrytown, New York) and the Sysmex E-4000 cytometer (Toa Medical Electronics Corp., Kobe, Japan).

\section{Apparatus}

Each cytometer was in full operation in the same laboratory and was operated by experienced technicians. No recalibration of the Sysmex E-4000 was necessary during the six weeks study. Haemoglobin concentration, red blood cell count, haematocrit and white blood cell count of the Technicon $\mathrm{H} 6000$ were calibrated daily, using the results from the Sysmex E-4000 for the quadruplicate analysis of a fresh sample from a person with haematologically normal results. Dividing the haemoglobin result of this sample in the Sysmex E- 4000 by 20.4 (mean normal $\mathrm{MCHC}$ ) gave the calibration value for the haematocrit in the Technicon $\mathrm{H} 6000$. A constant $\mathrm{MCHC}$ value was employed in the calibration of the haematocrit in order to avoid the influence of interindividual variability in measurement of the red blood cell volume by the impedance method. Both cytometers participated daily in an internal quality control programme, including Testpoint ${ }^{(\infty)}$ and Instrucontrol ${ }^{\oplus}$ low and high levels and five fresh normal blood samples. Further, we participate in national and regional external quality assessment programmes.

\section{Parameters}

Haemoglobin concentration, haematocrit, red blood cell count, mean corpuscular haemoglobin concentration (MCHC), mean cell volume (MCV), mean corpuscular haemoglobin $(\mathrm{MCH})$ and white blood cell count were collected from both cytometer $\dot{s}$ for further data analysis. In addition the relative distribution width (RDW) of the red blood cell histogram and percentages of granulocytes, large unstained cells (LUCs), lymphocytes, monocytes, eosinophils and basophils were collected from the Technicon $\mathrm{H} 6000$, together with the absolute distribution width (ADW) of the red blood cell histogram, percentages of large cell ratio, middle cell ratio and small cell ratio and occurrence of flagging from the Sysmex E-4000. The two flags concerned: 1. abnormality in the discriminator setting of the white blood cell histogram, which appears when the relative frequency at a discriminator in a through or at the lower or upper limits exceeds a preset limit, so that the reported result has a low reliability, and

2 . inability to determine a through discriminator-position between two white blood cell types, which leads to absence of three-part dif results. The absolute distribution width was defined in the Sysmex E-4000 as the distribution width of the red blood cell histogram at the $50 \%$ frequency level, taking the histogram peak as $100 \%$. Because the relative distribution width in the Technicon $\mathrm{H} 6000$ is defined as the CV of the red blood cell histogram, the absolute distribution width was calculated for this apparatus by multiplying the relative distribution width by $2 \mathrm{MCV} / 100$ for each sample.

\section{Data analysis}

The relationship between the results of the Sysmex and Technicon cytometers was calculated by the orthogonal regression analysis of Deming $(14,15)$. In addition the Pearson correlation coefficient $(r)$ was calculated for corresponding parameters. The significance of the differences between the mean results of both cytometers was tested in a two-tailed Stüdent's t-test. Flagged results were excluded from this calculations. 
We assayed the analytical performance of the small cell ratio, middle cell ratio and large cell ratio of the Sysmex E-4000 by calculating their sensitivity and specificity for corresponding results of the white blood cell series in the Technicon H6000 at rising decision limits of the three-part dif parameters. In addition to three-part dif results that exceeded a given decision limit, flagging was also regarded as an abnormal result. Current limits used in our laboratory when sorting out samples for microscopical examination were employcd for determination of abnormal results in the Technicon $H 6000$. Several rising limits werc employed for sorting out abnormal cosinophil or monocyte rates in order to show their influence on the analytical performance of the Sysmex E-4000.

\section{Results}

\section{Leukocyte parameters}

In table 1 the results of a comparison of the white blood cell parameters are shown. An excellent correlation and no significant difference was found between the white blood cell counts of the two cytometers, as well as between lymphocytc and small cell ratio percentages. Also the neutrophil and large cell ratio percentages correlated well. However, the mean large cell ratio percentage was significantly $3.1 \%$ higher than the mean neutrophil percentage, suggesting that other cells may also be implicated in the large cell ratio fraction. The combined value of neutrophils and large unstained cells in the Technicon H6000 correlated better with the large cell ratio percentage than the pure neutrophil percentage and, in addition, the difference between the means was smaller. In contrast, similar calculations with combinations of large unstained cells and lymphocytes or the sum of monocytes, eosinophils and basophils yielded less satisfactory results than with the proper cells. These findings indicate that white cells classified as large unstained cells in the Technicon H6000 are counted mainly with neutrophils as large cell ratio in the Sysmex E-4000. The correlation between monocyte, eosinophil or basophil rates with the middle cell ratio was significant but low, especially in the basophils, which contribute the least to this fraction.

For a better impression of the analytical performance of the three-population results of the Sysmex E-4000, the sensitivity and specificity for corresponding white blood cells counted with the Technicon $\mathrm{H} 6000$ were calculated at rising limits of the three-part dif parameters. As figure 1 shows, sensitivity as well as specificity of the small cell ratio to lymphocyte rates approached $100 \%$ within a narrow range of small cell ratio limits. This finding indicates that lymphocytes

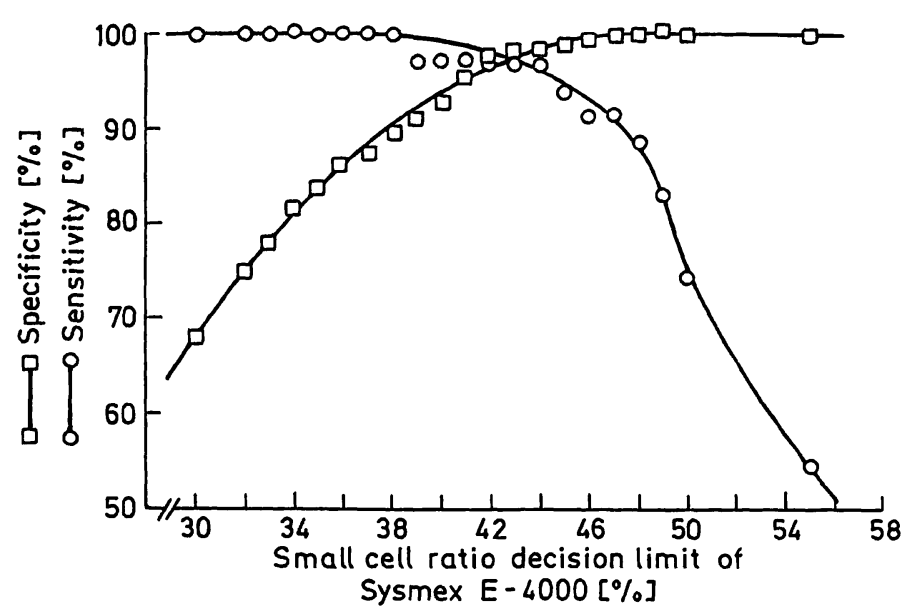

Fig. 1. Analytical performance of the Sysmex E-4000 in discrimination of increased lymphocyte rates.

Sensitivity and specificity are given as a function of the small cell ratio decision limit in the assay of 736 samples, of which $35(5 \%)$ contained $>46 \%$ lymphocytes.

Tab. 1. Comparison of white blood cell (WBC) count and differentiation obtained with Sysmex E-4000 and Technicon H6000 cytometers $(\mathrm{N}=622)^{*}$

\begin{tabular}{|c|c|c|c|c|c|c|c|c|}
\hline \multicolumn{2}{|l|}{ Parameter } & \multirow{2}{*}{$\begin{array}{l}\mathrm{H} 6000 \\
\bar{x} \pm \mathrm{SD}\end{array}$} & \multirow{2}{*}{$\begin{array}{l}E-4000 \\
\bar{y} \pm S D\end{array}$} & \multirow{2}{*}{$\begin{array}{l}\text { Differ- } \\
\text { ence } \\
\bar{y}-\bar{x}\end{array}$} & \multirow{2}{*}{$\begin{array}{l}\text { Student } t \\
\mathrm{P}\end{array}$} & \multirow{2}{*}{$\begin{array}{l}\text { Corre- } \\
\text { lation** } \\
\mathbf{r}\end{array}$} & \multicolumn{2}{|c|}{ Regression*** } \\
\hline $\mathrm{H} 6000$ & E-4000 & & & & & & $a$ & $b$ \\
\hline WBC & WBC $\left[10^{9} / 1\right]$. & $7.8 \pm 3.1$ & $7.8 \pm 3.1$ & -0.03 & n.s. & 0.99 & -0.08 & 1.01 \\
\hline Lymphocytes & SCR $[\%]$ & $25.6 \pm 10.5$ & $25.4 \pm 10.8$ & -0.20 & n.s. & 0.98 & -0.37 & 1.01 \\
\hline Neutrophils & LCR [\%] & $63.7 \pm 11.2$ & $66.8 \pm 11.7$ & 3.07 & $<0.001$ & 0.91 & 5.65 & 0.96 \\
\hline $\mathrm{MEB}^{* * * *}$ & $\operatorname{MCR}[\%]$ & $9.2 \pm 3.2$ & $7.5 \pm 4.3$ & -1.68 & $<0.001$ & 0.59 & 0.06 & 0.81 \\
\hline Lymphocytes + LUC $* * * *$ & SCR $[\%]$ & & & -1.47 & $<0.02$ & 0.96 & 0.08 & 0.94 \\
\hline Neutrophils + LUC**** & $\operatorname{LCR}[\%]$ & & & 1.79 & $<0.01$ & 0.94 & -3.94 & 1.09 \\
\hline $\mathrm{MEB}+\mathrm{LUC} * * * *$ & $\operatorname{MCR}[\%]$ & & & -2.96 & $<0.001$ & 0.49 & -0.14 & 0.73 \\
\hline Monocytes & MCR $[\%]$ & & & & & 0.47 & & \\
\hline Eosinophils & MCR $[\%]$ & & & & & 0.40 & & \\
\hline Basophils & MCR $[\%]$ & & & & & 0.22 & & \\
\hline
\end{tabular}

* $\quad \mathrm{N}$ for white blood cells and lymphocyles (692) are higher because of inability or abnormality of discrininalor setting between MCR and LCR.

** All Pearson correlation coefficients were signilicant ( $p<0.001$ ).

*** Orthogonal regression of $y=a+b x ; y=$ result $E-4000, x=$ result $H 6000$.

**** MEB: Monocytes + eosinophils + basophils $\quad$ LUC $=$ large unstained cell in Technicon H6000 differentiation. 
are counted sensitively and specifically in the small cell fraction. The sensitivity of the large cell ratio (fig. 2) also attained $100 \%$, but the specificity approached a maximal value of $80 \%$, which supports the supposition that other cells are counted with the neutrophils in the large cell fraction.

In figure 3, sensitivity and specificity in relation to the middle cell ratio decision limit are indicated for eosinophils. In samples with $>5 \%$ eosinophils the sensitivity decreased quickly, when the middle cell ratio upper limit was raised to improve the specificity. The specificity did not reach $100 \%$, which can be attributed to the mixed population of the middle cell fraction. However, when the classification limit of samples with abnormal results of eosinophils was increased from $5 \%$ to $7 \%, 9 \%$ or $11 \%$, then the sensitivity of the middle cell ratio increased sharply, while the specificity diminished only slightly. Taking $2 \%, 5 \%$ and $8 \%$ as upper normal limits for basophils, eosinophils and monocytes, respectively, an upper normal limit of $12 \%$ was calculated for the middle cell ratio with orthogonal regression, using the constants in table 1 . From figure 3 it is clear that only samples with more than $10 \%$ eosinophils were detected with a sensitivity of more than $90 \%$ at this middle cell ratio limit, while the specificity amounted $68 \%$.

The dependency of sensitivity and specificity on middle cell ratio decision limits for several rising classification limits of monocytes is shown in figure 4 . The results agreed with those for eosinophils. At the $12 \%$ middle cell ratio upper limit only samples with more than $10 \%$ monocytes were traced with a sensitivity of more than $90 \%$, while the specificity amounted to $70 \%$.

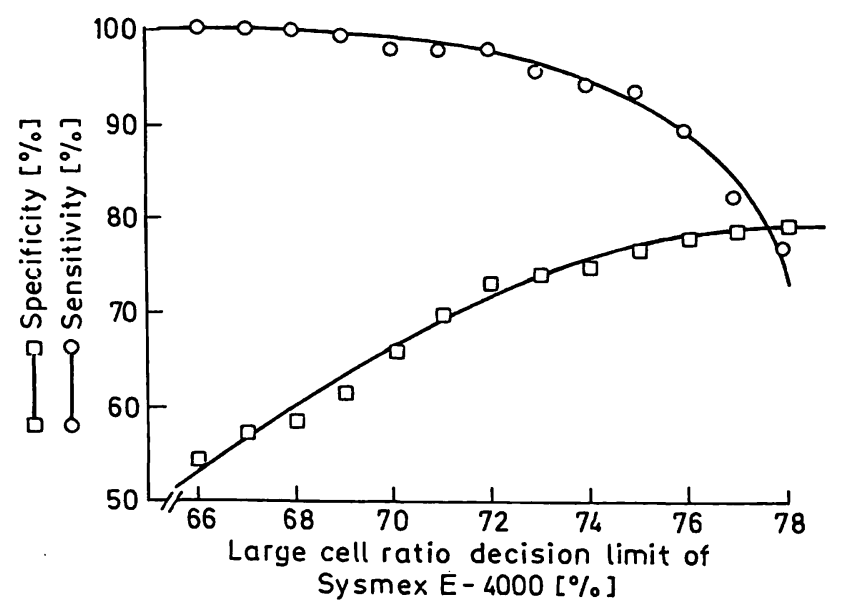

Fig. 2. Analytical performance of the Sysmex E-4000 in discrimination of increased neutrophil rates.

Sensitivity and specificity are given as a function of the large cell ratio decision limit in the assay of 695 samples, of which $192(28 \%)$ contained $>71 \%$ neutrophils.

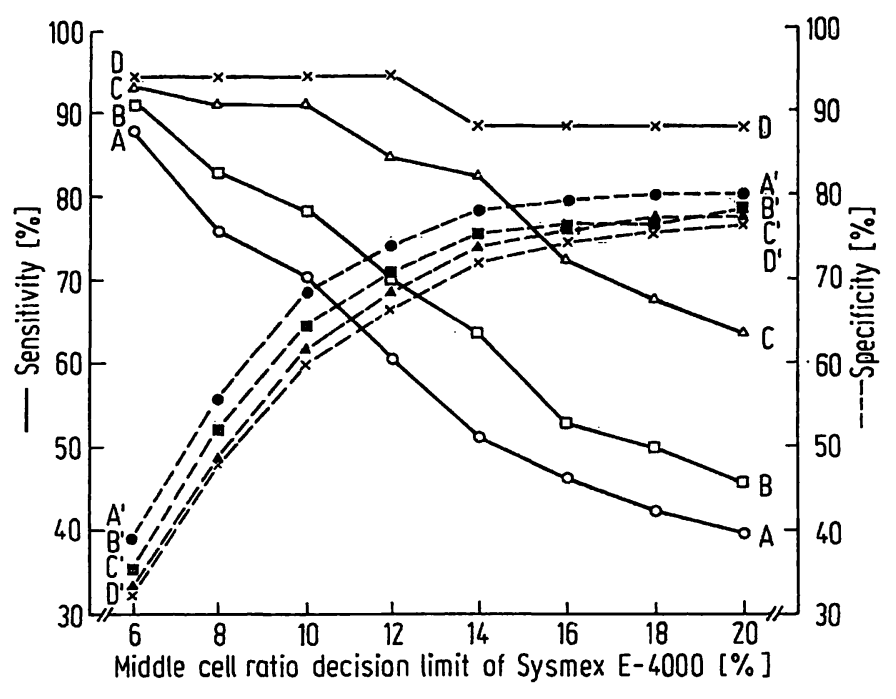

Fig. 3. Analytical performance of the Sysmex E-4000 in discrimination of increased eosinophil rates.

Sensitivity $(\longrightarrow)$ and specificity $(----)$ are given as a function of the middle cell ratio decision limit in the assay of 764 samples, of which 202 samples contained $>5 \%$ eosinophils (A O-O, $A^{\prime} 0-0$ ), 102 contained $>7 \%$ (B $\left.\square-\square), B^{\prime} \square-\square\right), 47$ contained $>9 \%$ eosinophils $\left.(C \Delta-\Delta), C^{\prime} \Delta-\Delta\right)$ and 18 contained $>11 \%$ eosinophils $\left(\mathrm{D} x-\mathrm{x}, \mathrm{D}^{\prime} \mathrm{x}-\mathrm{x}\right)$.

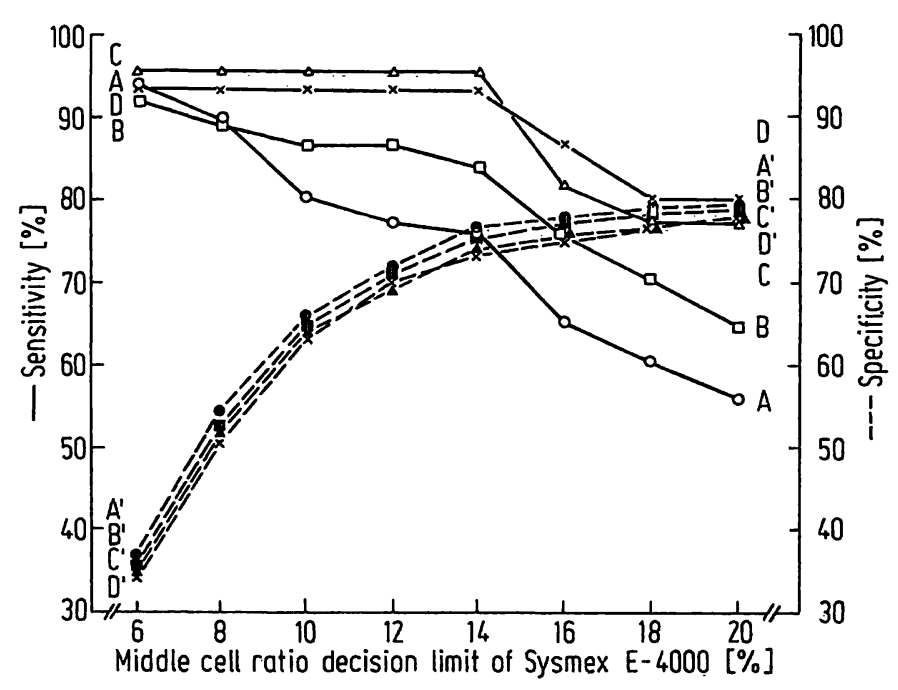

Fig. 4. Analytical performance of the Sysmex E-4000 in discrimination of increased monocyte rates.

Sensitivity $(\longrightarrow)$ and specificity $(----)$ are given as a function of the middle cell ratio decision limit in the assay of 717 samples, of which 66 samples contained $>8 \%$ monocytes ( $\mathrm{A} \circ-0$ ), $\left.\mathrm{A}^{\prime}-0-0\right), 37$ contained $>9 \%$ monocytes (B $\left.\square-\square, B^{\prime} \mathbf{a}-\square\right), 22$ contained $>10 \%$ monocytes $\left(C \Delta-\Delta, C^{\prime} \Delta-\Delta\right)$, and 15 contained $>11 \%$ monocytes $\left(D_{x}-x, D^{\prime} x-x\right)$.

Since flagging on the E-4000 was interpreted as indicative of an abnormality in the screening of abnormal white blood cell pictures, the frequency and variability of flagging were tested by running 70 samples in duplicate (tab. 2). In $70 \%$ of the samples the flagging result was the same both times. In $54 \%$, flagging was absent from both duplicate runs, $20 \%$ showed various types of flagging in both duplicate 
runs, and $26 \%$ showed flagging only once. Flags occurred almost exclusively in the large cell ratio and middle cell ratio fractions. The small cell ratio was flagged in only 3 out of 695 samples.

\section{Erythrocyte parameters}

Table 3 presents results of the comparison of red blood cell parameters. Haemoglobin concentration, red blood cell count and consequently mean cell haemoglobin $(\mathrm{MCH})$ showed a very good correlation. Moreover, no significant difference between the means of this parameters on both cytometers was found. Although there was also a good correlation between the haematocrit and $\mathrm{MCV}$ from both cytometers, the mean haematocrit was 0.0051 higher in the Sysmex and the mean MCV $2.19 \mathrm{fl}$ higher. Differences between the mean corpuscular volume (MCV) measured with Sysmex E-4000, and with Technicon $\mathrm{H} 6000$ in

Tab. 2. Incidence of flags in 70 samples tested in duplicate for flagging frequency on the Sysmex E-4000 cytometer.

\begin{tabular}{lrc}
\hline Result in both tests* & $\mathrm{N}$ & (Frequency) \\
\hline Conform & 49 & $(70.0 \%)$ \\
No flag & 38 & $(54.3 \%)$ \\
Flag 1 & 8 & $(11.4 \%)$ \\
Flag 2 & 3 & $(4.3 \%)$ \\
Different & 21 & $(30.0 \%)$ \\
Flag 1/flag 2 & 3 & $(4.3 \%)$ \\
Flag 1/no flag & 8 & $(11.4 \%)$ \\
Flag 2/no flag & 10 & $(14.3 \%)$ \\
\hline
\end{tabular}

* flag 1: abnormality in a discriminator setting of the white blood cell histogram, appearing when the relative frequency at a discriminator in a through or at the lower or upper limits exceeds a preset limit, so that the reported result has a low reliability.

flag 2: inability to determine a through discriminator position between two white blood cell types, which leads to absence of a three-part dif result.

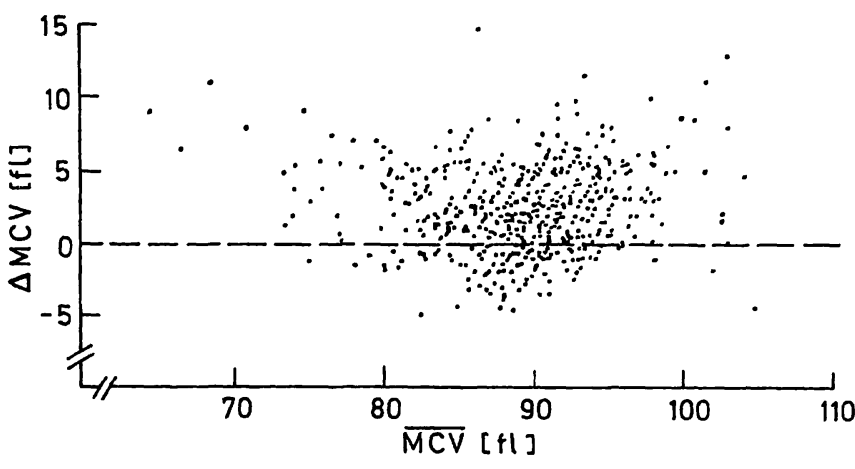

Fig. 5. Difference in the mean corpuscular volume (MCV) in relation to the average MCV per sample measured with both cytometers.

Ordinate: MCV Sysmex minus MCV Technicon, measured in the same sample;

Abscissa: (MCV Sysmex + MCV Technicon) $/ 2$ in the same sample.

the same sample were plotted versus the mean $\mathrm{MCV}$ of each sample. As shown in figure 5, the mean difference was not constant over the whole volume range of the red cells. In normocytic cells the mean difference was minimal, but it increased in the microcytic as well as in the macrocytic range. Moreover, $\triangle \mathrm{MCV}$ varied widely between samples even at a given $\mathrm{MCV}$. In the normal MCV range, the maximal difference between individual $\triangle \mathrm{MCV}$ values was $15 \mathrm{fl}$.

To find out, how the variability of $\triangle \mathrm{MCV}$ could be explained, we plotted the MCV of the samples against the mean of the $\mathrm{MCH}$ measured in each sample for both cytometers. $\mathrm{MCH}$ was taken as a measure of the size of the red cells, because no significant difference and a good correlation between the $\mathrm{MCH}$ of both cytometers was found. As figure 6 shows, the plots are shifted, and they are different for each cytometer. In both graphs the deflection starts at about $1.70 \mathrm{fmol} \mathrm{MCH}$. For each cytometer, the orthogonal regression and the correlation constant of the relation $\mathrm{MCV}-\mathrm{MCH}$ were calculated separately for samples with $\mathrm{MCH}<1.70 \mathrm{fmol}$ and $\mathrm{MCH} \geqslant 1.70 \mathrm{fmol}$. The

Tab. 3. Comparison of red blood cell results obtained with Sysmex E-4000 and Technicon H6000 cytometers $(\mathrm{N}=693)$

\begin{tabular}{|c|c|c|c|c|c|c|c|}
\hline \multirow[t]{2}{*}{ Parameter } & \multirow{2}{*}{$\begin{array}{l}H 6000 \\
\bar{x} \pm S D\end{array}$} & \multirow{2}{*}{$\begin{array}{l}E-4000 \\
\bar{y} \pm S D\end{array}$} & \multirow{2}{*}{$\begin{array}{l}\text { Difference } \\
\bar{y}-\bar{x}\end{array}$} & \multirow{2}{*}{$\begin{array}{l}\text { Student t } \\
\mathrm{p}\end{array}$} & \multirow{2}{*}{$\begin{array}{l}\text { Corre- } \\
\text { lation** } \\
\mathrm{r}\end{array}$} & \multicolumn{2}{|c|}{ Regression*** } \\
\hline & & & & & & a & $\mathrm{b}$ \\
\hline $\mathrm{Hb}[\mathrm{mmol} / \mathrm{l}]$ & $8.34 \pm 1.21$ & $8.30 \pm 1.21$ & 0.04 & n.s. & 0.99 & -0.06 & 1.00 \\
\hline Haematocrit & $0.402 \pm 0.058$ & $0.407 \pm 0.055$ & 0.0051 & $<0.02$ & 0.96 & 0.0174 & 0.97 \\
\hline $\mathrm{RBC}\left[10^{12} / 1\right]$ & $4.55 \pm 0.62$ & $4.52 \pm 0.63$ & -0.03 & n.s. & 0.98 & -0.15 & 1.02 \\
\hline $\operatorname{MCV}[\mathrm{fl}]$ & $88.1 \pm 5.3$ & \pm 5.47 & 2.19 & $<0.001$ & 0.87 & 6.49 & 0.95 \\
\hline $\mathrm{MCH}$ [fmol] & \pm 0.13 & \pm 0.14 & 0.00 & n.s. & 0.94 & -0.005 & 1.01 \\
\hline $\mathrm{MCHC}[\mathrm{mmol} / \mathrm{l}]$ & \pm 0.48 & \pm 0.73 & -0.39 & $<0.001$ & 0.30 & & \\
\hline ADW [II]* & $30.0 \pm 1.73$ & \pm 3.35 & -1.17 & $<0.001$ & 0.50 & -29.6 & 1.95 \\
\hline
\end{tabular}

* See methods for calculation of absolute distribution width (ADW).

** All correlation coefficients were significant $(p<0.001)$.

*** Orthogonal regression of $y=a+b x$, where $y=$ result by $E-4000$ and $x=$ result by $H 6000$. 
regression constant (a) of cells with $\mathrm{MCH} \geqslant 1.70$ fmol measured with Sysmex E-4000 ( $a=55.6$; $r=0.82)$ and cells with $\mathrm{MCH}<1.70 \mathrm{fmol}$ measured with Technicon $\mathrm{H} 6000(\mathrm{a}=53.6 ; \mathrm{r}=0.95)$ agreed best. In figure 6 the orthogonal regression of MCV $\mathrm{MCH}$ for these cells is represented with a dotted line. With Sysmex a higher MCV than this was found in cells with $\mathrm{MCH}<1.70 \mathrm{fmol}(\mathrm{a}=48.3 ; \mathrm{r}=0.79)$. On the other hand, with Technicon, a lower MCV was measured in cells with $\mathrm{MCH} \geqslant 1.70 \mathrm{fmol}$ $(\mathrm{a}=41.5 ; \mathrm{r}=0.92)$.

Further, it appeared that the spread of MCV values in relation to $\mathrm{MCH}$ was smaller with the Technicon than with the Sysmex.
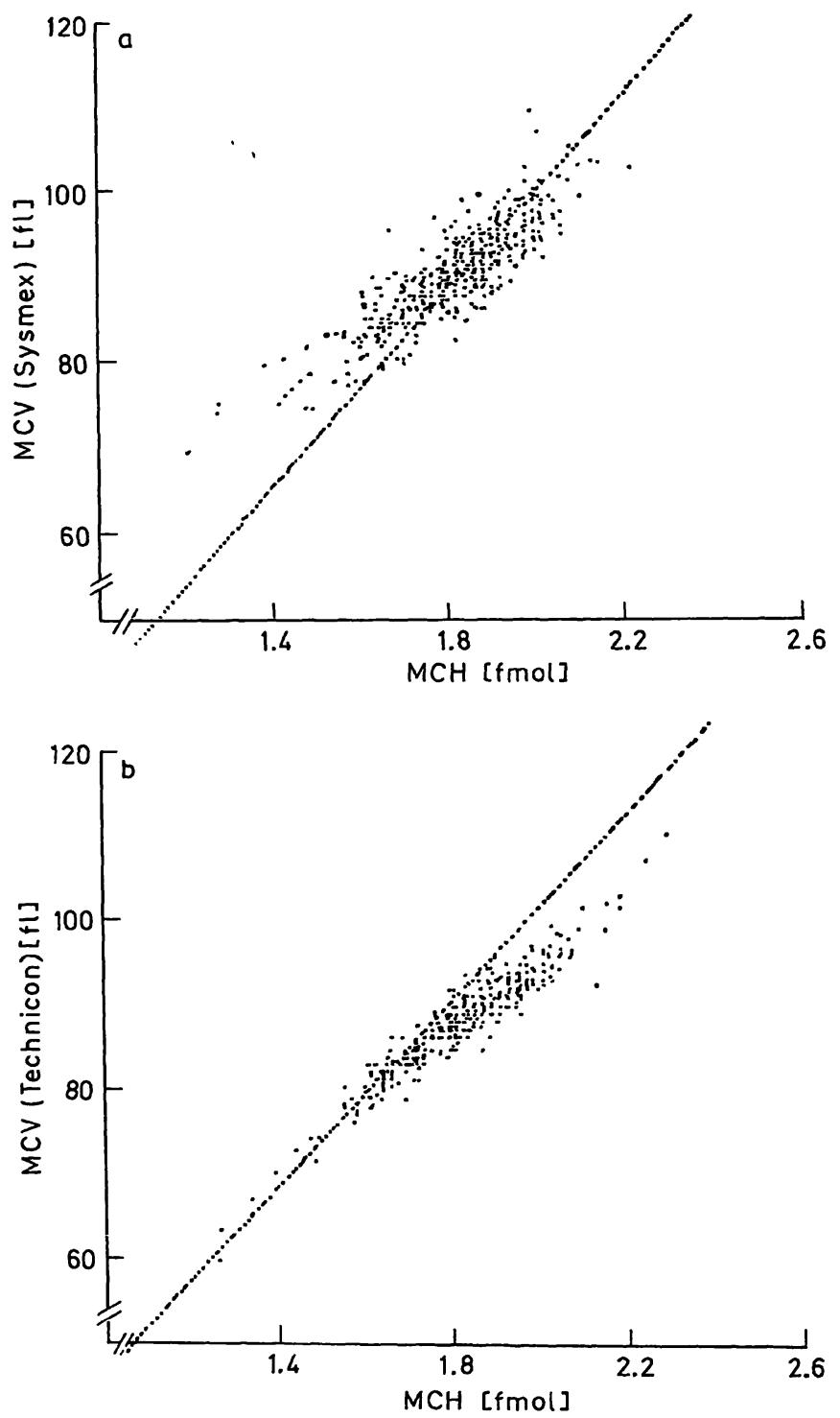

Fig. 6. Relation between mean corpuscular volume (MCV) and mean corpuscular hacmoglobin $(\mathrm{MCH})$.
a) Sysmex E-4000
b) Technicon $\mathrm{H} 6000$.

The dotted lines represent the relation $\mathrm{MCV}=-12.9$ $+55.6 \mathrm{MCH}$ for cells with $\mathrm{MCH} \geqslant 1.70 \mathrm{fmol}$ measured with Sysmex (a), and MCV $=-6.8+53.6 \mathrm{MCH}$ for cells with $\mathrm{MCH}<1.70 \mathrm{fmol}$ measured with Technicon (b). For further comment, see text.
In the Sysmex the mean MCHC was $0.39 \mathrm{mmol} / \mathrm{l}$ lower and its SD considerably higher than in the Technicon (tab. 3). Moreover there was only a low correlation between the mean corpuscular haemoglobin concentration (MCHC) on both cytometers. In agreement with the mutually deviate relation between $\mathrm{MCV}$ and $\mathrm{MCH}$ in both cytometers, a different relation between $\mathrm{MCHC}$ and $\mathrm{MCH}$ was found for both cytometers (fig. 7). In the Sysmex no significant correlation between $\mathrm{MCHC}$ and $\mathrm{MCH}$ existed in samples with $\mathrm{MCH} \geqslant 1.70 \mathrm{fmol}(\mathrm{r}=0.18,0.05<\mathrm{p}<0.10)$, but there was a significant correlation ( $r=0.64$, $\mathrm{p}<0.001)$ in samples with low $\mathrm{MCH}$. In the Technicon a significant, but very low correlation $(r=0.21$, $\mathrm{p}<0.05$ ) existed in samples with low $\mathrm{MCH}$ and a significant correlation $(r=0.63, p<0.001)$ in samples with $\mathrm{MCH} \geqslant 1.70 \mathrm{fmol}$.

We also found a low correlation between the absolute distribution width measured on both cytometers (tab. 3), which may likewise relate to the deviate measurement of the volume of microcytic and macrocytic cells with both cytometers.
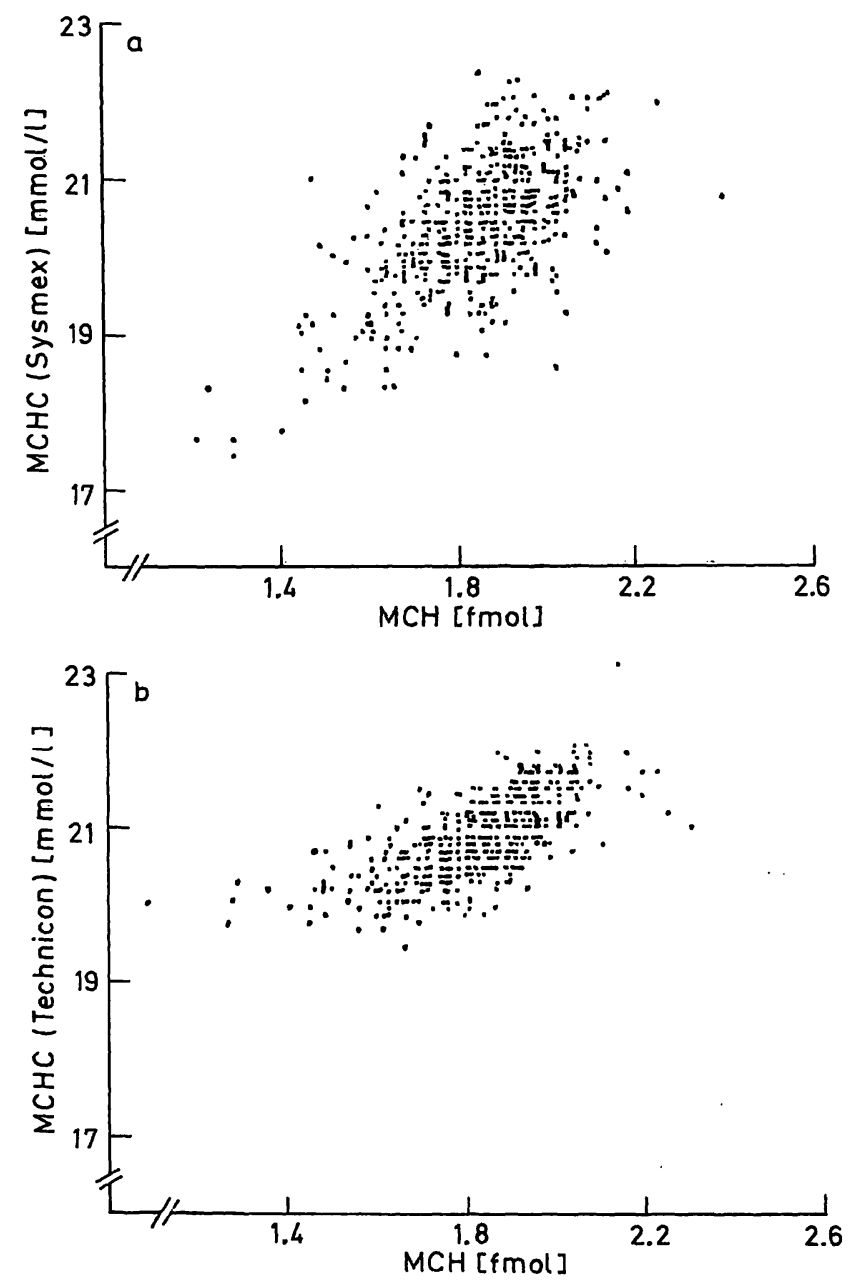

Fig. 7. Relation between mean corpuscular haemoglobin concentration (MCHC) and mean corpuscular haemoglobin $(\mathrm{MCH})$.

$\begin{array}{ll}\text { a) Sysmex E-4000 } & \text { b) Technicon } \mathrm{H} 6000 \text {. }\end{array}$ 


\section{Discussion}

The good performance of cytochemical cytometers when counting, sizing and differentiating blood cells has made them valuable screening tools for segregating normal samples from those requiring additional testing, but they entail rather high investment and consumer costs (16). Less sophisticated alternatives are available with instruments based on mere measurement of particle volume with aperture-impedance or light-scattering methods, which supply an abridged white blood cell differential in addition to counting and sizing of cells. Volume analysis of white blood cells under controlled conditions causing differential shrinkage of the leukocyte series, procures generally a differentiation in three populations $(2,17,18)$. When the Sysmex E-4000 based on this principle was recently introduced, we were interested in comparing the performance of this so-called three-part dif with that of the Technicon H6000 cytochemical cytometer, which is used in our laboratory.

In addition to the excellent agreement between the small cell ratio of Sysmex and the lymphocyte rate of Technicon, we found that the small cell ratio was highly sensitive and specific when discriminating normal from abnormal lymphocyte rates assayed with the Technicon H6000.

The large cell ratio of the Sysmex presented high sensitivity for increased rates of neutrophils and good correlation with neutrophilic rates as well, but the specificity of the large cell ratio for normal results did not exceed $80 \%$ at any large cell ratio cut-off level. The mean large cell ratio was on average $3 \%$ higher than the percentage neutrophils. These findings indicate that other cells usually contribute a few percent to the large cell ratio fraction. These are partly cells counted as large unstained cells in Technicon, because the combined rate of neutrophils and large unstained cells correlated better with the large cell ratio and deviated on average less from the large cell ratio than the mere neutrophil percentage.

Although the middle cell ratio correlated significantly with the percentage of eosinophils, monocytes or basophils, the performance of the middle-cell fraction in screening increased rates of this cells was rather poor. Only samples with $10 \%$ or more eosinophils or monocytes could be traced with a sensitivity of more than $90 \%$ at the $12 \%$ upper cut-off level for middle cell ratio. Samples with less than $10 \%$ eosinophils or monocytes are traced with markedly lower sensitivity. Lowering the middle cell ratio cut-off level did not improve the results, because this greatly reduced the specificity. The counting of a mixed population of monocytes, eosinophils and basophils showed why the specificity of the middle cell ratio normal results of each of the separate cell types did not exceed $85 \%$. The middle cell ratio and large cell ratio were relative frequently flagged, in contrast with the small cell ratio. Moreover, the incidence of discordant flagging in $30 \%$ of the duplicate tests suggests that discrimination between middle cell ratio and large cell ratio populations is often problematic. This may be another cause for the lesser performance of the middle cell ratio.

Our finding of the frequent occurrence of flagging indicates that sorting white blood cells into three populations by means of mere volume analysis frequently presents problems in samples obtained in a hospital. Difficulties may be expected e.g. in samples containing erythroblasts, in patients with leukaemia or with cytostatical therapy, where cells with abnormal morphology and size occur.

In a concurrent study of the sensitivity of the Sysmex E-4000 to several deviations detected in microscopical examination (19), we found an incidence of flagging varying from $30 \%$ to $35 \%$ (samples showing left shift) and of increased large cell ratio percentage of flagging varying from $77 \%$ to $90 \%$ (samples with toxic granulation, immature neutrophils or qualitative red blood cell abnormalities of several kinds). Sixty four percent of samples containing erythroblasts were flagged and each of the three white blood cell populations showed an increased ratio or a flag in $73 \%$ of these samples, indicating that erythroblasts may be counted in all of three white blood cell populations. In the present study we found indications that atypical lymphocytes and blasts, counted in the large unstained cell fraction of the Technicon H6000, are largely implicated in the large cell ratio fraction. All these findings suggest that caution should be exercised in interpreting three-part dif results in samples with cell morphology deviating from normal.

Findings similar to those in this study have been reported earlier for the correlation of results of manual differential counts and three-part difs assayed with other cytometers based on aperture-impedance (2022), as well as those based on light-scattering methods (23). The correlation coefficients varied between 0.91 and 0.98 for lymphocytes (typical and variant lymphocytes), between 0.94 and 0.99 for granulocytes (segmented neutrophils and bands), and between 0.56 and 0.65 for mononuclear cells. However, these studies disagree about the incorporation of eosinophils. basophils or immature granulocytes in the granulocyte or mononuclear fractions.

A good correlation between the results from the Coulter S-plus II and those from the two cytochemical 
cytometers Hemalog D and Technicon $\mathrm{H} 6000$ has also been reported for the determination of the lymphocyte percentage (24).

As in other studies with cytometers based on the aperture-impedance method, we found that the Sysmex E-4000 showed good accuracy in the determination of the $\mathrm{Hb}$ concentration, red blood cell counts and consequently the mean cell haemoglobin. However, discrepancies existed for parameters relating to the measurement of the erythrocyte volume.

Firstly the mean haematocrit was higher and the mean MCHC was lower in the Sysmex than in the Technicon. A comparative study of data from the Coulter S-plus and the Technicon $\mathrm{H} 6000$ also revealed that the haematocrit and MCV were significantly higher and the MCHC significantly lower with the Coulter S-plus (25). MCV, haematocrit and micro haematocrit corrected for trapped plasma were also higher in the Coulter $S$ than in the Hemac (Ortho), another instrument based on a light-scattering method (26).

Secondly, a great interindividual variation of the difference between the MCV measured with Sysmex and with Technicon appeared in our study. The difference amounted to $15 \mathrm{fl}$ and was related to the magnitude of the MCV. Variable interindividual differences of $\mathrm{MCV}$, when measured with the Coulter S-plus, or when calculated from the micro haematocrit and the red blood cell count given by the Coulter ZB I, have been reported previously (18). These differences varied from -4 to $+6 \mathrm{fl}$ and were not related to the $\mathrm{MCV}$. In addition, we found that at a given $\mathrm{MCH}$, the variation of $\mathrm{MCV}$, and consequently of $\mathrm{MCHC}$, was much higher in the Sysmex than in the Technicon. We can only speculate on an explanation of these findings. Imprecision of both cytometers can hardly account for this variability, because the intra-assay S. D. of the MCV for normal samples was only 0.28 $\mathrm{fl}$ with the Sysmex and $0.14 \mathrm{fl}$ with the Technicon.

The pulse height produced by a given particle in an impedance cytometer depends, apart from its volume, also on its shape and orientation in the electric field $(27-30)$. While the shape factor of prolate ellipsoids approaches 1 , it amounts to 1.5 for spheres, which means that the impedance signal overestimates the particle volume of spheres by $50 \%$ and of ellipsoids by $6 \%$. Cells with reduced deformability lack more or less the ability to take a fusiform shape when they are subjected to shear stress in the sample stream traversing the sensing orifice, and they therefore cause a higher pulse height. Decreased red blood cell deformability can diminish seriously the accuracy of the MCV in impedance cytometers (31). Decreased de- formability has been reported in a variety of states: microcytic hypochromic anaemia due to iron deficiency $(31,32)$, autoimmune haemolytic anaemia (33), hereditary spherocytosis $(33,34)$, abnormal haemoglobins (33), red blood cell enzymopathies (33), desiccytosis (35), sickle cell disease $(32,36,37)$, HbCC disease $(33,38)$, pyropoikilocytosis (39), aging of red blood cells (40), cell storage (41) and diabetes mellitus (32). The deformability is affected by the surface/ volume ratio, the internal viscosity relating to the $\mathrm{MCHC}$, and the visco-elastic properties of the membrane of the red blood cell $(42-45)$. Discrepancies between the MCV measured with impedance cytometers and derived from the micro haematocrit occur also in conditions, which produce hyperosmolar plasma, e. g. in hyperglycaemia or uraemia (46-47). Possibly the relatively great variability of the MCV and $\mathrm{MCHC}$ in the Sysmex cytometer compared with the Technicon may be partly explained by inter-individual variation of red blood cell deformability and the effect of the osmolability of the diluent in relation to the in vivo osmotic condition of the cells.

Measurement of the red blood cell volume with a light-scattering method is less sensitive to abnormalities in cell deformability, but discrepancies with the micro haematocrit method have been reported. For $\mathrm{MCHC}$ values above $22.3 \mathrm{mmol} / \mathrm{l}$ the $\mathrm{MCHC}$ is underestimated with increasing error as the true $\mathrm{MCHC}$ increases, while for MCHC values below 18.6 $\mathrm{mmol} / \mathrm{l}$ the $\mathrm{MCHC}$ is overestimated as result of a deviate refractive index connected with the $\mathrm{Hb}$ concentration of the cells (31). This leads to spuriously constant values for the $\mathrm{MCHC}$ in optical cytometers and may be another explanation for our finding that the variation of $\mathrm{MCV}$ and $\mathrm{MCHC}$ in relation to $\mathrm{MCH}$ in the Technicon $\mathrm{H} 6000$ was smaller than in the Sysmex E-4000. Different effects of particularly low erythrocyte $\mathrm{Hb}$ concentrations on the measured cell volume in cytometers based on different methods (31) are possibly responsible for the relatively great variation in $\triangle \mathrm{MCV}$ that we found.

The relation between $\mathrm{MCV}$ and $\mathrm{MCH}$ of cells with normal or high $\mathrm{MCH}$ assayed with the Sysmex agreed well with that of cells with low MCH in the Technicon. Compared with the Technicon, the Sysmex E-4000 overestimated the MCV in samples with $\mathrm{MCH}<1.70$ fmol, while the difference increased at decreasing $\mathrm{MCH}$. Analogous to this finding, an inverse relation between $\mathrm{MCH}$ and the amount of trapped plasma in the micro haematocrit has been demonstrated in samples of patients with iron deficiency and a $\mathrm{MCH}$ lower than 1.5 fmol $(48,49)$. Increase of trapped plasma is effected by the deformability of red blood cells (50). 
Decreased deformability of cells with low $\mathrm{MCH}$ could also explain the overestimation of MCV by the Sysmex cytometer at low $\mathrm{MCH}$, as suggested by the similar relation to the $\mathrm{MCH}$. Decreased deformability of red blood cells is well known in microcytic anaemia $(31,32)$. Therefore, the lower MCHC results, which we found with the Sysmex in microcytic cells, may be caused at least partly by decreased deformability of cells with low $\mathrm{MCH}$.

In the Technicon $\mathrm{H}-6000$, the correlation between $\mathrm{MCV}$ and $\mathrm{MCH}$ decreased in normocytic and macrocytic cells. Measurement of light scattering of a series of red blood cell samples of various mammalian species after sphering and fixing has shown that the measured signal increases less than expected from a linear relation with the MCV (51). With software revision $\mathrm{N}$, which was in use in our Technicon $\mathrm{H} 6000$, the deviation from a linear relation is corrected for cell volumes above $95 \mathrm{fl}$ (52). However, we found a deflection from a linear relation between MCV and $\mathrm{MCH}$, which started at a lower MCV and remained constant above $95 \mathrm{fl}$. Both phenomena, increased measurement of the MCV of cells with low $\mathrm{MCH}$ in the impedance cytometer and insufficient correction of the signal of larger cells in the optical cytometer, can explain the MCV differences between the Sysmex and Technicon instruments.

Different results for the $\mathrm{MCV}$, depending on the method used, have consequences for the value of MCHC, produced by different cytometers. While the MCHC did not correlate with the $\mathrm{MCH}$ in normal and macrocytic cells in the Sysmex, a significant relation to the $\mathrm{MCH}$ existed in small cells, in contrast

\section{References}

1. Lombarts, A. J. P. F., Koevoet, A. L. \& Leijnse, B. (1986) Ann. Clin. Biochem. 23, 390-404.

2. Williams, L. J. (1984) J. Med. Technol. 1, 189-196.

3. Rümke, C. L. (1978) Iñ: Differential leucocyte counting (Koepke, J. A., ed.) pp. 39-46, College of American Pathologists.

4. Rümke, C. L., Bezemèr, P. D. \& Kuik, D. J. (1975) J. Chronic. Dis. 28, 661-668.

5. England, J. M. (1979) Clin. Lab. Haematol. 1, 263-273.

6. Connelly, D. P., McC̣lain, M. P., Crowson, T. W. \& Benson, E. S. (1982) Hum. Pathol. 13, 294-300.

7. Rich, E. C., Crowson, T. W. \& Connelly, D. P. (1983) J. Am. Med. Ass. 249, 633-636.

8. Dutcher, T. F. (1984) Clin. Lab. Med. 4, 71-87.

9. Wielders, J. P. M., Beunis, M. H. \& van Wersch, J. W. J. (1986) J. Clin. Chem. Clin. Biochem. 24, 471-480.

10. Hasty, T., Harris, L. G., Stonacek, S. M. \& Frazier, B. (19.82) J. Clin. Lab. Automation 2, 408-415.

11. Kaplow, L., Orlowski, L. \& Vaznelis, M. E. (1983) J. Clin. Lab. Automation 3, 167-174.

12. Kim, J. R. \& Ornstein, L. (1983) Cytometry 3, 419-427.

13. Loken, M. R., Parks, D. R. \& Herzenberg, L. A. (1977) J. Histochem. Cytochem. 25, 790-795. with the Technicon, where only a very low correlation was found in small cells and a significant relation in larger cells.

\section{Conclusion}

In conclusion, the Sysmex E-4000 showed a good performance in counting total white blood cells, lymphocytes and neutrophils compared with the Technicon $\mathrm{H} 6000$. The utility of the middle cell ratio is limited. Only samples with more than $10 \%$ eosinophils, monocytes or basophils were traced with a sensitivity of more than $90 \%$ and an acceptable specificity. The Sysmex E-4000 may be well fitted for longitudinally monitoring neutrophil and lymphocyte rates in patients with no abnormal cell morphology. Further use in white blood cell differentiation should be limited to identifying those samples that need microscopical examination.

The red blood cell results of both cytometers agreed very well except for parameters based on volume measurement. Differences of the MCV measured with both instruments showed a great interindividual variability. The differences of MCV between both cytometers increased in macrocytic as well as in microcytic cells. MCV and MCHC values measured with the Sysmex E-4000 exhibited more interindividual variation and a different relation to the $\mathrm{MCH}$ values than those measured with the Technicon H6000. Different measuring principles in haemocytometry may result therefore in deviating results for $\mathrm{MCV}, \mathrm{HCHC}$ and abolute distribution width. Variation of red blood cell properties in normal and pathological states probably influence the estimation of the cell volume.

14. Cornbleet, P. J. \& Gochman, N. (1979) Clin. Chem. 25, $432-438$.

15. Deming, W. E. (1943) Statistical Adjustment of Data, p. 184, John Wiley and Sons, New York.

16. Maschand, A., Van Leute, F. \& Galen, R. S. (1983) J. Clin. Lab. Aut. 3, 19-26.

17. Rowan, R. M. (1983) Blood cell volume analysis. A new screening technology for the haematologist, pp. 1-56, A. Clark and Co., London.

18. Richardson Jones, A. (1982) In: Advances in Hematological Methods: The blood count (van Assendelft, O. W. \& England, J. M., eds.) pp. 49-72, CRC Press, Boca Raton, Florida.

19. Smeets, E. H. J. \& van Wersch, J. W. J. (1987) Ann. Clin. Biochem. 24, Suppl 2, p. 144.

20. Nelson, L., Charache, S., Keyser, E. \& Metzger, P. (1985) J. Clin. Pathol. 83, 547-554.

21. Griswold, D. J. \& Champagne, V. D. (1984) Am. J. Clin. Pathol. 84, 49-57.

22. Kalish, R. J. \& Becker, K. (1986) Am. J. Clin. Pathol. 86, $751-755$.

23. Tisdall, Ph. A. (1985) Lab. Med. 16, 228- 233. 
24. Forestier, F., Amirault, P., Carré, C., Sassier, P. \& Potron, G. (1984) Nouv. Rev. Fr. Hetatol. 26, 39-43.

25. Cave, R. J., Holder, R. L., Morris, T. K., Taylor, J., Smith D. \& Shinton, N. K. (1983) Clin. Lab. Haematol. 5, $203-$ 214.

26. Lewis, S. M. \& Bentley, S. A. (1977) J. Clin. Pathol. 30, 54.

27. Fricke, H. (1953) J. Appl. Phys. 24, 644-646.

28. Kachel, V. (1979) In: Flow Cytometry and Sorting (Melamed, M. R., Mullaney, P. F. \& Mendelsohn, M. L., eds.) pp. 61-104, John Wiley and Sons, New York.

29. Bator, J. M., Groves, M. R., Price, B. J. \& Eckstein, E. C. (1984) Cytometry 5, 34-41.

30. Bagge, K., Branemark, P. I., Karlsson, R. \& Skalak, R. (1980) Blood Cells 6, $231-237$.

31. Mohandas, N., Clark, M. R., Kissinger, S., Bayer, C. \& Shohet, S. B. (1980) Blood 56, 125-128.

32. Bator, J. M., Groves, M. R., Price, B. J. \& Eckstein, E. C. (1984) Cytometry 5, 34-41.

33. Allard, C., Mohandas, N. \& Bessis, M. (1977) Blood Cells 3, 209-221.

34. Groner, W., Mohandas, N. \& Bessis, M. (1980) Clin. Chem. 26, 1435- 1442 .

35. Clark, M. R., Mohandas, N., Caggiano, V. \& Shohet, S. B. (1978) J. Supramol. Struct. 8, 521 - 532.

36. Bessis, M. \& Mohandas, N. (1977) Blood Cells 3, 229239.

37. Clark, M. R., Mohandas, N. \& Shohet, S. B. (1980) J. Clin. Invest. $65,189-196$.
38. Mohandas, N., Philips, W. M. \& Bessis, M. (1979) Sem. Hematol. 16, 95-114.

39. Walter, T., Mentzer, W., Greenquist, W., Schrier, S. \& Mohandas, N. (1977) Blood 50 (suppl 1) 98.

40. Feo, C. J. (1979) Nouv. Rev. Fr. Hematol, 21 (Suppl) 60.

41. England, J. M. \& Down, M. C. (1982) In: Advances in Hematological Methods: the Blood Cónt (van Assendelft, O. W. \& England, J. M., eds.) pp. 29-35, CRC Press, Boca Raton, Florida.

42. Mohandas, N., Clark, M. R., Jacobs, M. S., Groner, W. \& Shohet, S. B. (1980) Blood Cells 6, 329-344.

43. Herrera, A. \& Feo, C. J. (1984) Nouv. Rev. Fr. Hematol. 26, $169-177$.

44. Evans, E., Mohandas, N. \& Leung, A. (1984) J. Clin. Invest. 73, 477-488.

45. Marcel, G. A. \& Lague, G. (1979) Nouv. Presse Med. 8, 4077.

46. Beautyman, W. \& Bills, T. (1974) Lancet $I I, 905-906$.

47. Savage, R. A. (1983) Am. J. Clin. Pathol. 80 (Suppl.) 626632.

48. Pearson, Th. C. \& Guthrie, D. L. (1982) Am. J. Clin. Pathol. 78, 770-772.

49. England, J. M., Walford, F. M. \& Waters, D. A. W. (1972) Br. J. Haematol. 23, 247-256.

50. Sirs, J. A. (1968) Biorheology 5, 1-14.

51. Groner, W. \& Tyeko, D. (1980) Blood Cells 6, 141

52. Technicon bulletin (1983) 365/83, Technicon Instruments Corp., Tarrytown, New York.

Drs. E. H. J. Smeets

Hematological Laboratory

De Wever Ziekenhuis

P. O. Box 4446

NL-6401 CX Heerlen 